\title{
Medievalista
}

Online

$19 \mid 2016$

Número 19

Tese de Doutoramento em História da Arte, especialidade em História da Arte Medieval, apresentada à Faculdade de Ciências Sociais e Humanas da Universidade Nova de Lisboa, Novembro de 2014. Orientação do Professor Doutor José Custódio Vieira da Silva (FCSHUNL)

\section{Dinis del Portogallo e Isabel d'Aragona in vita e in morte. Creazione e trasmissione della memoria nel contesto storico e artistico europeo}

D. Dinis of Portugal and Isabel of Aragon in vita and in morte. Memory creation and transmission in the European artistic and historical context

\section{Giulia Rossi Vairo}

\section{(2) OpenEdition}

Journals

\section{Edição electrónica}

URL: http://journals.openedition.org/medievalista/1033

DOI: $10.4000 /$ medievalista.1033

ISSN: $1646-740 \mathrm{X}$

\section{Editora}

Instituto de Estudos Medievais - FCSH-UNL

\section{Refêrencia eletrónica}

Giulia Rossi Vairo, « D. Dinis del Portogallo e Isabel d'Aragona in vita e in morte. Creazione e trasmissione della memoria nel contesto storico e artistico europeo », Medievalista [Online], 19 | 2016, posto online no dia 01 junho 2016, consultado o 23 setembro 2020. URL : http://

journals.openedition.org/medievalista/1033; DOI : https://doi.org/10.4000/medievalista.1033

\section{(c) (7) (8)}

Mediavalista está licenciado com uma Licença Creative Commons - Atribuição-NãoComercial 4.0 Internacional. 
Título: D. Dinis del Portogallo $e$ Isabel d'Aragona in vita $e$ in morte. Creazione $e$ trasmissione della memoria nel contesto storico e artistico europeo | D. Dinis of Portugal and Isabel of Aragon in vita and in morte. Memory creation and transmission in the European artistic and historical context.

Tese de Doutoramento em História da Arte, especialidade em História da Arte Medieval, apresentada à Faculdade de Ciências Sociais e Humanas da Universidade Nova de Lisboa, Novembro de 2014. Orientação do Professor Doutor José Custódio Vieira da Silva (FCSHUNL).

Autor(es): Giulia Rossi Vairo

Universidade: Universidade Nova de Lisboa

Faculdade e Departamento / Unidade de Investigação: Instituto de Estudos Medievais Código Postal: 1069-061

Cidade: Lisboa

País: Portugal

Contacto: g.rossivairo@tiscali.it

Fonte: Medievalista [Em linha]. Dir. Bernardo Vasconcelos e Sousa. Lisboa: IEM.

Disponível em: http://www2.fcsh.unl.pt/iem/medievalista/vario1909.html

ISSN: 1646-740X

Data recepção do texto: 22 de Outubro de 2015 
D. Dinis del portogallo e Isabel d'Aragona in vita e in morte. Creazione e trasmissione della memoria nel contesto storico e artistico europeo - Giulia Rossi Vairo

\section{Apresentação de Tesel Thesis Presentation}

D. Dinis del Portogallo $e$ Isabel d'Aragona in vita $e$ in morte. Creazione $e$ trasmissione della memoria nel contesto storico e artistico europeo,

Tese de Doutoramento em História da Arte, especialidade em História da Arte Medieval, apresentada à Faculdade de Ciências Sociais e Humanas da Universidade Nova de Lisboa, Novembro de 2014. Orientação do Professor Doutor José Custódio Vieira da Silva (FCSH-UNL).

\section{Giulia Rossi Vairo}

\section{O tema}

A Tese gira à volta das vidas e das personalidades de um rei e de uma rainha, D. Dinis e D. Isabel, soberanos de Portugal entre os finais do século XIII e o primeiro quartel do XIV, figuras míticas da História e da Cultura portuguesas. Em particular, este trabalho incide sobre o processo de criação e de transmissão da memória, elaborado e posto em prática pelos reis ao longo da sua existência. O acto final deste processo foi a realização dos seus monumentos fúnebres criados para serem conservados o túmulo do rei, na igreja do mosteiro cisterciense de S. Dinis e S. Bernardo de Odivelas (Figura 1), e o túmulo da rainha, na igreja do mosteiro de Sta. Clara e Sta. Isabel de Coimbra (Figura 2). 
D. Dinis del portogallo e Isabel d'Aragona in vita e in morte. Creazione e trasmissione della memoria nel contesto storico e artistico europeo • Giulia Rossi Vairo

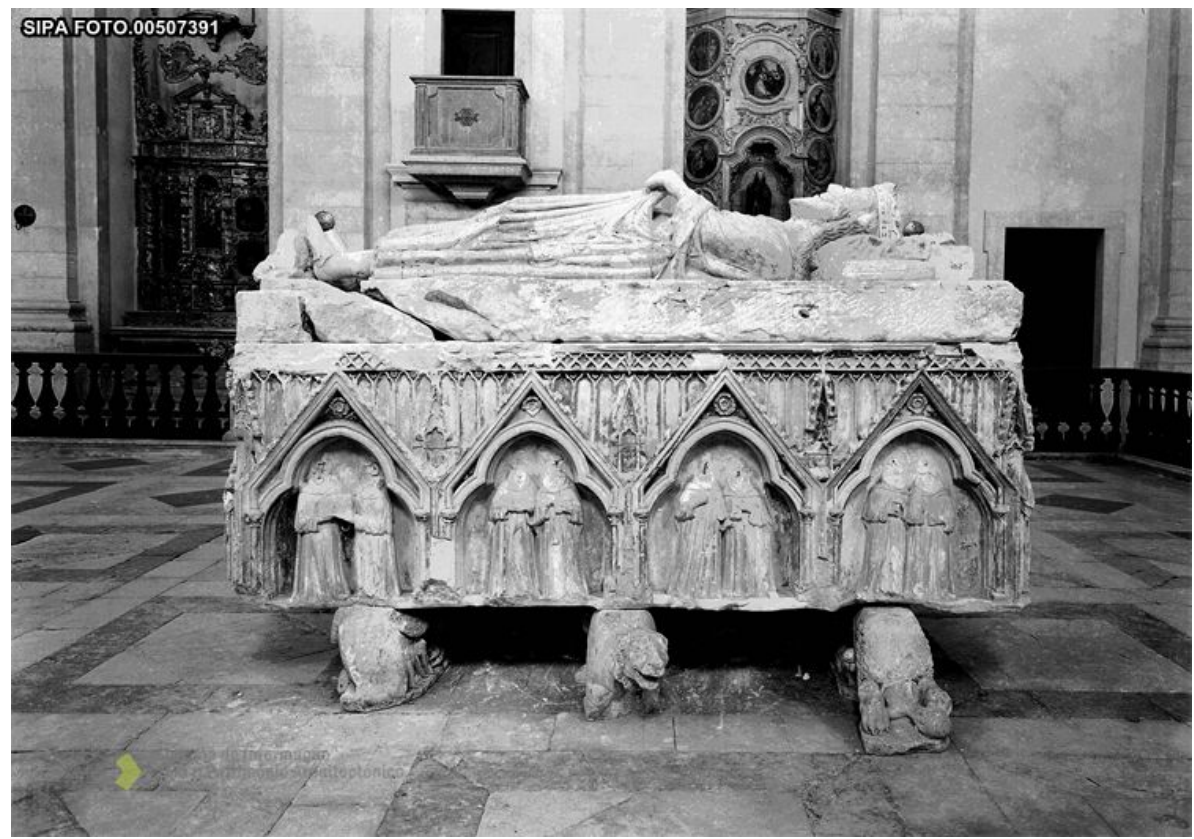

Figura 1 - Túmulo do rei D. Dinis. Odivelas, igreja de S. Dinis, hoje na capela do Evangelho

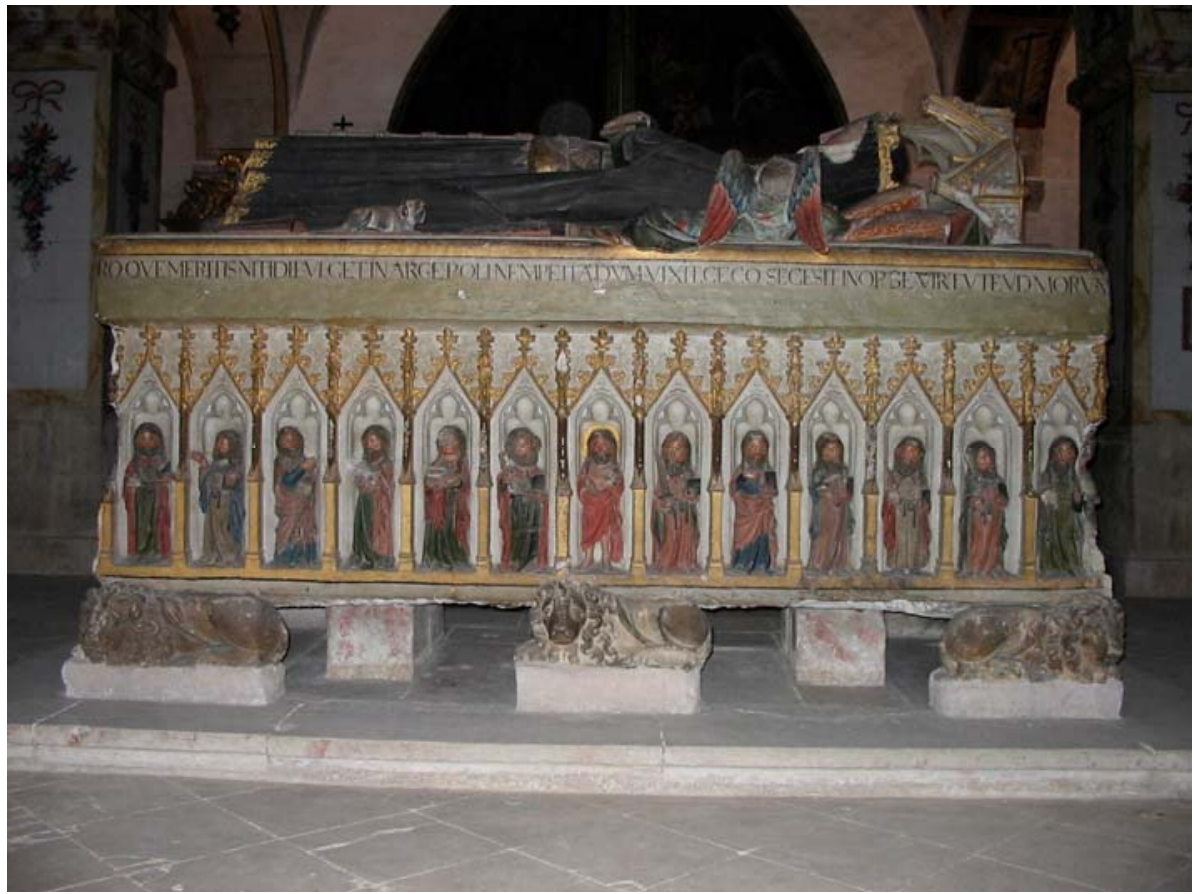

Figura 2 - Túmulo de D. Isabel de Aragão. Coimbra, igreja do mosteiro de Santa Claraa-Nova, coro baixo 
D. Dinis del portogallo e Isabel d'Aragona in vita e in morte. Creazione e trasmissione della memoria nel contesto storico e artistico europeo - Giulia Rossi Vairo

Para além do fascínio que estas duas ilustres personagens exerceram sobre mim, numa leitura retrospetiva deste estudo, poderia afirmar que esta investigação teve o seu ponto de partida na observação e na constatação das numerosas diferenças existentes entre os dois sepulcros régios a partir do seu actual estado de conservação, mas sobretudo a nível de feição. Efectivamente, os dois sarcófagos apresentam programas iconográficos diversos, foram realizados por mestres diferentes e destinaram-se a dois mosteiros de observância distinta e geograficamente distantes, circunstâncias totalmente inéditas em Portugal até àquele momento. Portanto, os cônjuges decidiram separar-se in morte e, de certo modo, assim permanecerão na recordação dos vindouros, sendo a primeira vez que isto se verificava no reino. Relativamente à tradição anterior, outro facto inédito foi o de D. Dinis e D. Isabel terem encomendado e terem visto terminados in vita os monumentos que deveriam eternizar a sua memória in morte. Por outro lado, como se tornou evidente ao longo da investigação, os sepulcros foram concebidos a priori como parte integrante do projecto monumental mais vasto constituído pelos edifícios monásticos que os teriam custodiado e cuja fundação, em ambos os casos, foi da responsabilidade dos soberanos.

Entre as motivações na base da escolha deste não fácil tema, considerando a tradição historiográfica e a complexidade das figuras dos dois protagonistas, esteve o propósito de restituir ao reino de Portugal dionisino a sua "dimensão europeia", querendo contribuir para fazer dissipar de vez o preconceito historiográfico que ainda hoje interpreta o reino de Portugal medievo como uma realidade periférica, recolhida sobre si mesma "entre as fronteiras nacionais mais antigas da Europa". De facto, não obstante um difícil exórdio, o Portugal de D. Dinis tornou-se numa monarquia estável, uma potência entre as potências da época, uma realidade geopolítica definida, economicamente sólida, culturalmente diversificada e vivaz, aberta à recepção de influências e de estímulos provenientes do exterior. Nesta perspectiva, os sepulcros régios dão testemunho desta conjuntura favorável podendo ser classificados justamente como obras-primas da escultura medieval europeia, não só portuguesa, da primeira metade do século XIV. 
D. Dinis del portogallo e Isabel d'Aragona in vita e in morte. Creazione e trasmissione della memoria nel contesto storico e artistico europeo - Giulia Rossi Vairo

\section{A estrutura}

Os limites cronológicos deste estudo coincidem grosso modo com o reinado de D. Dinis (1279-1325), embora, nalguns capítulos, ao narrar a vida da rainha e as decisões tomadas por ela após a morte do consorte, a cronologia se estenda por mais alguns anos.

A Tese estrutura-se em três partes que correspondem a três diversas fases da vida dos protagonistas, entendida em sentido lato: In vita, A crise e In morte.

A I ${ }^{\text {a }}$ Parte serve de introdução e de premissa fundamental, de tipo histórico mas também metodológico, para a abordagem dos temas desenvolvidos. De facto, inicia-se com uma análise das problemáticas relações entre a Monarquia portuguesa e a Sé Apostólica no momento da subida ao trono do herdeiro de Afonso III, bem mais condicionantes das dinâmicas internas do reino, quer antes, quer depois da ascensão de D. Dinis, e com uma importância maior do que a que até hoje lhes tem sido atribuída. A seguir, foram abordadas a pietas, a religiosidade e a espiritualidade de D. Dinis e D. Isabel e as iniciativas empreendidas, em conjunto ou separadamente, a favor das diversas comunidades religiosas do reino. Entre estas, esteve a fundação do mosteiro de S. Dinis e S. Bernardo de Odivelas, instituído no fim do século XIII e confiado ao ramo feminino da ordem cisterciense, resultado de uma ideal convergência de interesses e de uma partilha de intentos entre o poder régio, o monástico e o episcopal. A I ${ }^{\mathrm{a}}$ Parte encerra com uma reflexão sobre a reconquista do espaço sagrado por parte dos soberanos Dinis e Isabel, primeiros expoentes da Coroa portuguesa a ultrapassarem o limiar do templo mais de um século depois do nascimento da Monarquia, cumpridas que foram as condições para que isso acontecesse.

A II ${ }^{\mathrm{a}}$ Parte intitula-se de maneira significativa de "A crise" e abrange o arco cronológico da guerra civil durante a qual se assistiu às desavenças entre D. Dinis e o infante D. Afonso, inicialmente apoiado pela mãe, a rainha consorte D. Isabel, no seu acto de rebelião para com o rei. A necessidade de tratar o tema da guerra civil deriva do facto de, a meu ver, ter existido uma relação de causa-efeito entre o conflito e o processo de criação, construção e transmissão da memória do casal régio. Após um status quaestionis da historiografia sobre o argumento, foram indagados os antecedentes (1316-1318) e o desenvolvimento da guerra, sobretudo da primeira fase (1319-1322) 
D. Dinis del portogallo e Isabel d'Aragona in vita e in morte. Creazione e trasmissione della memoria nel contesto storico e artistico europeo - Giulia Rossi Vairo

com base no estudo aprofundado das fontes narrativas e arquivísticas, evidenciando as lacunas e as omissões na reconstrução dos acontecimentos até hoje proporcionada pelos historiadores. O fulcro desta $\mathrm{II}^{\mathrm{a}}$ Parte é a breve vida do panteão régio de Odivelas (1318-1322), instituído na tentativa de aplacar a discórdia surgida nos anos anteriores entre os diversos componentes da família real e o projecto monumental que este originariamente contemplava (Figura 3). Este previa a realização de um mausoléu duplo para celebrar a memória dos cônjuges, sendo destinado a ser colocado no centro da igreja, entre o coro e o altar mor. O novo panteão da Coroa foi inaugurado pelo túmulo do infante D. Dinis, filho dos príncipes Afonso e Beatriz e herdeiro do reino, falecido em 1318, que hoje se encontra no mesmo edifício, na capela da Epístola.

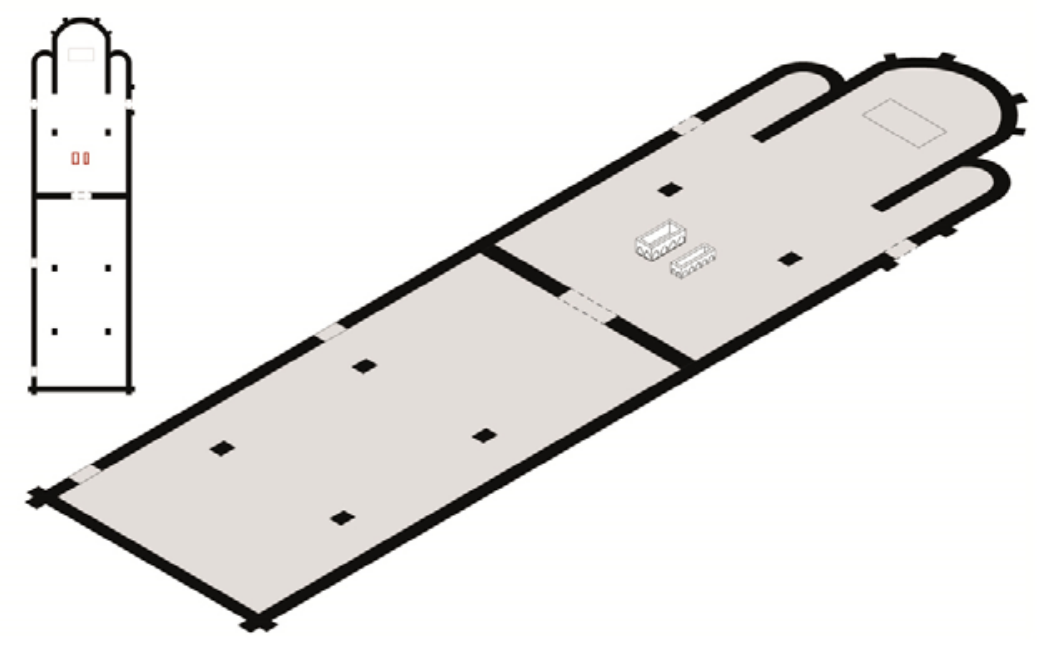

Figura 3 - Igreja de S. Dinis e S. Bernardo de Odivelas. Projecto monumental dos reis

Dinis e Isabel (projecto: Giulia Rossi Vairo; elaboração gráfica: arq. Alessandra Perluigi)

Entre as outras consequências da guerra, para além da frustração do panteão de Odivelas, deve salientar-se a decisão da rainha consorte Isabel de legar a sua memória individual ao mosteiro de Sta. Clara e Sta. Isabel de Coimbra, escolhido como sua última morada.

A III ${ }^{\mathrm{a}}$ e última Parte apresenta, primeiro, uma reflexão sobre os espaços que acolheram os corpos dos reis, isto é: a igreja-mausoléu de S. Dinis e S. Bernardo de Odivelas, no 
D. Dinis del portogallo e Isabel d'Aragona in vita e in morte. Creazione e trasmissione della memoria nel contesto storico e artistico europeo - Giulia Rossi Vairo

caso de D. Dinis, a capela funerária na igreja de Sta. Clara e Sta. Isabel de Coimbra, no caso de D. Isabel. A este propósito, mereceu particular atenção o complexo processo de amadurecimento espiritual da rainha, influenciado também pelas experiências vividas, que culminou, nos últimos anos da sua existência, na disposição de ser sepultada no interior do coro da igreja do mosteiro das clarissas, vontade que não foi respeitada pelos seus executores testamenteiros. Segue a análise monográfica dos sepulcros régios em que foram lidos e interpretados os programas iconográficos que ornamentam os sarcófagos, desde os suportes até os jacentes, pondo em confronto as diferentes opções dos cônjuges. Nomeadamente, deteve-se no processo de concepção e cronologia das obras, nos mestres envolvidos e nos destinatários, para além dos defuntos e nas mensagens de que os monumentos fúnebres foram investidos.

\section{As fontes}

Ao longo dos anos da investigação foram examinadas fontes materiais e iconográficas, para além das literárias e arquivísticas, consideradas com valor de "documentos" e cuja observação, leitura e interpretação se revelaram de fundamental importância para a redação final da Tese. Os próprios monumentos fúnebres não representaram somente o objecto de estudo, constituindo os instrumentos privilegiados para a comemoração dos defuntos e, portanto, para a transmissão da sua memória, mas também fontes materiais, autênticos "documentos e testemunhos" e portadores de uma mensagem precisa. Nesta mesma perspectiva, foram estudadas as arquitecturas, os espaços e as estruturas, consciente de que, em ausência de documentos mais explícitos, as pedras falam.

Tratando-se de uma Tese de história da arte, obrigatório foi o recurso às fontes iconográficas, desde as iluminuras, as gravuras, os desenhos até aos selos e as fotografias antigas. Além disso, tendo em conta os protagonistas e a necessidade de reconstruir o contexto histórico de referência, recorreu-se a fontes narrativas e literárias, cronologicamente datáveis do séc. XIV ao séc. XIX, entre as quais se destacam as crónicas dos séculos XIV-XVI - Crónica Geral de Espanha de 1344, Crónica de Portugal de 1419 e Crónica de D. Dinis, inserida na Crónica dos sete primeiros reis de Portugal de Rui de Pina - e também o Livro que fala da boa vida que fez a Raynha de 
D. Dinis del portogallo e Isabel d'Aragona in vita e in morte. Creazione e trasmissione della memoria nel contesto storico e artistico europeo • Giulia Rossi Vairo

Portugal Dona Isabel e dos seus bõons feitos e milagres em sa vida e depoys sa morte, popularmente conhecido como a Lenda da Rainha Santa.

Por fim, fundamental foi o estudo das fontes arquivísticas coligidas durante a pesquisa levada a cabo no Arquivo Nacional da Torre do Tombo, no Arquivo Secreto Vaticano e no Archivo General de la Corona de Aragón. Embora o recurso à documentação de arquivo esteja presente ao longo de todo o texto no aparato crítico, contemplando as mais variadas tipologias de documento - registos, instrumentos notariais, autos de natureza económica (doações, escambos, compras etc.), cartas régias, breves apostólicos - integra a Tese um Apêndice documental que apresenta uma seleção restrita dos documentos estudados (64) abrangendo um arco cronológico que vai de 1289 a 1325. Os documentos, redigidos em latim e em português, foram coligidos no Arquivo Nacional da Torre do Tombo (17), na Biblioteca Nacional de Portugal (1) e sobretudo no Arquivo Secreto Vaticano (46). Trata-se na maioria de fontes inéditas ou nunca transcritas na íntegra, cuja leitura e interpretação se tornou determinante para a construção do raciocínio e, por consequência, do texto.

\section{A metodologia}

A metodologia adoptada nesta Tese resulta de uma abordagem inter e pluridisciplinar que passa pela História, a História da Arte, a História das Mentalidades, a História da Espiritualidade, a História da Santidade medieval, até à Teologia, utilizando-se ainda diversas disciplinas auxiliares como a Arquivística, a Paleografia, a Diplomática e a Sigilografia. No caso específico, o estudo da espiritualidade e da religiosidade dos soberanos que, pelo menos até uma certa data, caminharam a par e passo para depois tomarem caminhos distintos, revelou-se como uma das possíveis chaves de leitura para a interpretação da produção artística e arquitectónica ligada à encomenda régia.

Para além disso, o trabalho inscreve-se numa perspectiva internacional e transnacional, tendo por diversas ocasiões ultrapassado os confins do reino de Portugal e estabelecido analogias e confrontos pontuais com outros contextos dinásticos europeus, com o objectivo de considerar o que acontecia na realidade portuguesa no âmbito do quadro mais vasto da Europa medieval. Em particular, pressuposto metodológico deste estudo 
D. Dinis del portogallo e Isabel d'Aragona in vita e in morte. Creazione e trasmissione della memoria nel contesto storico e artistico europeo - Giulia Rossi Vairo

foi o ter considerado o reino de Portugal do fim do séc. XIII - primeira metade do XIV, perfeitamente reentrante no âmbito de influência mediterrânica. Localizado na periferia do mundo medieval, solidamente "ancorado à terra" para a sua inserção na Península Ibérica, mas ao mesmo tempo aberto para o Oceano Atlântico, o Portugal de D. Dinis esteve cultural, económica e politicamente ligado ao mundo mediterrânico. Partindo desta premissa conceptual, estabeleceram-se relações com as monarquias da órbita mediterrânica pretendendo restituir ao Portugal dionisino a sua faceta mediterrânica, desde sempre subvalorizada relativamente à atlântica, ou seja com os reinos de Castela, Aragão, Nápoles, Sicília, França, mas também com a Sé Apostólica, antes e depois da sua transferência para Avinhão. As relações da Coroa com o Papado foram constantemente evocadas ao longo deste estudo, também porque, em circunstâncias específicas, a intervenção pontifícia se revelou determinante para as dinâmicas e os equilíbrios dentro do reino.

Contudo, todas as teses e as hipóteses histórico-artísticas formuladas neste trabalho foram resultado do "imperativo categórico" do historiador de arte, ou seja, de uma prolongada, repetida e "obstinada" observação das obras de arte, túmulo ou edifício que fosse, a que se seguiu a necessária contextualização no tempo e no espaço de referência, estando convencida de que as obras de arte são sempre o produto e o reflexo de um preciso momento histórico e da concomitância de diversos factores, internos e externos ao próprio objecto.

\section{O objecto}

Do ponto de vista estritamente histórico-artístico, no centro deste trabalho esteve uma restrita seleção de obras de escultura e de arquitectura directamente ligadas à encomenda régia. No total, examinaram-se cinco túmulos, todos realizados entre $1318 \mathrm{e}$ 1328 ca., emblemáticos da qualidade e da variedade da produção escultórica portuguesa da primeira metade do século XIV, de que foram fornecidas leituras inéditas dos programas iconográficos e da história contextual: o monumento fúnebre do rei D. Dinis; a arca anónima n. Inv. 75 Esc do Museu Arqueológico do Carmo de Lisboa, atribuída à rainha consorte Isabel quando ainda previa a sepultura em Odivelas junto do marido 
D. Dinis del portogallo e Isabel d'Aragona in vita e in morte. Creazione e trasmissione della memoria nel contesto storico e artistico europeo • Giulia Rossi Vairo

(Figura 4); o túmulo do infante D. Dinis, filho do herdeiro do trono Afonso e da princesa Beatriz (1317-1318); o sepulcro da infanta D. Isabel (1324-1326), filha dos reis Afonso e Beatriz; e o mausoléu da rainha Isabel em Coimbra - amplas digressões, quer do ponto de vista histórico, quer arquitectónico, foram dedicadas aos "contentores" dos sepulcros analisados, o mosteiro de S. Dinis de Odivelas e o mosteiro de Sta. Clara de Coimbra.

No geral, consideraram-se os monumentos fúnebres em análise não só como instrumentos privilegiados para a comemoração do defunto, mas também como portadores de uma mensagem precisa (religiosa, teológica, simbólica, alegórica, pedagógica, social e política), dirigida a todos os que teriam gozado da sua visão ao frequentarem as igrejas dos mosteiros escolhidos pelos reis como última morada.

\section{Os resultados}

Para os monumentos fúnebres procedeu-se, assim:

- a novas atribuições relativamente ao destinatário inicial, como no caso do túmulo do infante Dinis, filho dos príncipes Afonso e Beatriz, conservado em Odivelas, antigamente associado a uma filha ilegítima de D. Dinis, mais recentemente ao infante João, filho dos reis Afonso IV e Beatriz, e no caso da arca n. 75 do MAC de Lisboa, ainda hoje ligada ao nome de Constança Manuel, esposa do infante Pedro, futuro rei D. Pedro I, mas por mim considerada como a "primeira opção" da rainha Isabel quando ainda pensava mandar-se sepultar em Odivelas, uma vez constatadas as evidentes analogias da sua iconografia com o mausoléu de D. Dinis (Figura 4);

Medievalista online № 19| Janeiro - Junho 2016 @ IEM - Instituto de Estudos Medievais 10 

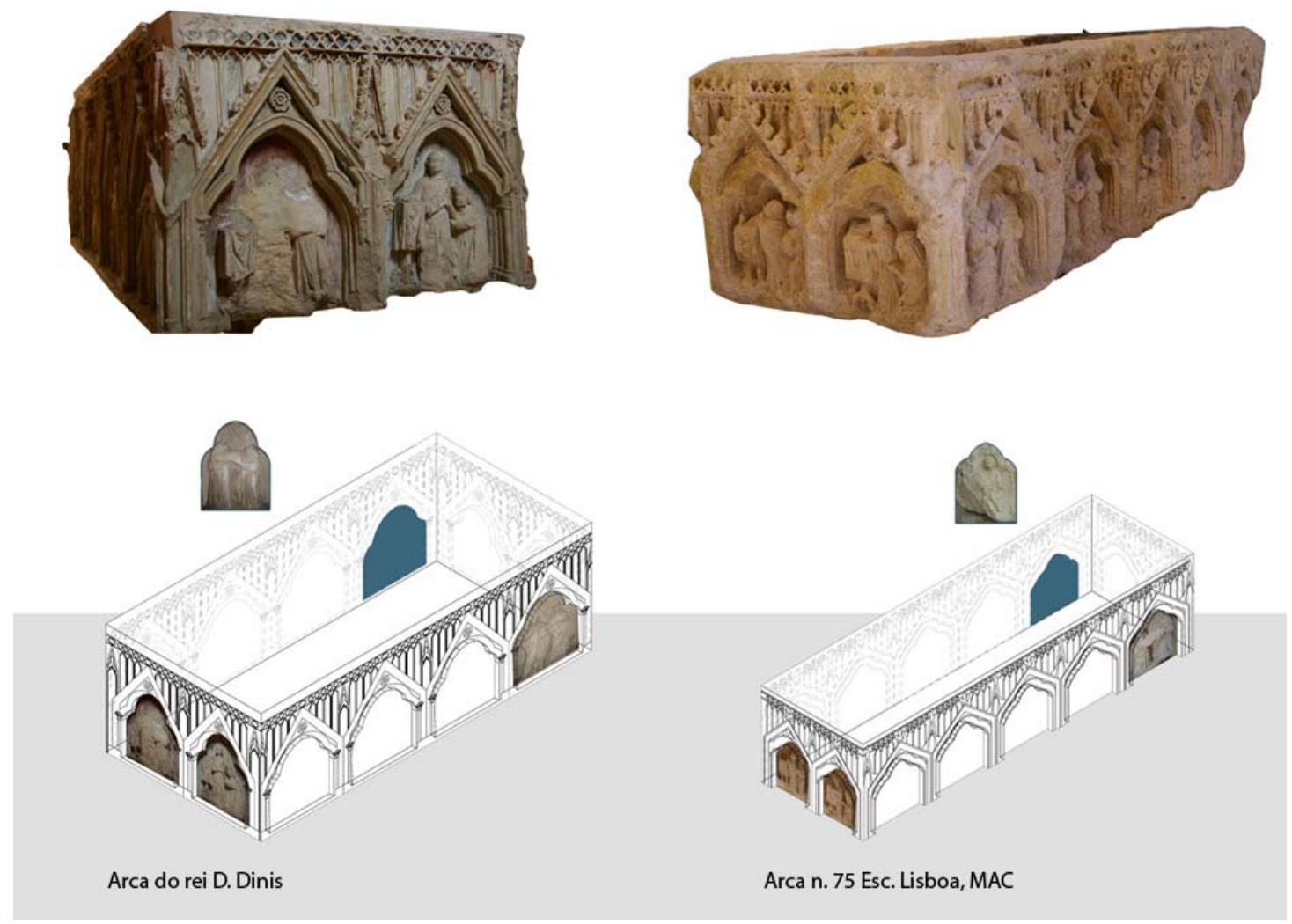

Figura 4 - Arca n. inv. 75 Esc del Museu Arqueológico do Carmo, Lisboa, e arca de D. Dinis a confronto (elaboração gráfica: arq. Alessandra Perluigi)

- a novas leituras dos programas iconográficos esculpidos, como no caso do túmulo do rei, uma espécie de "sermão por imagens" inspirado na estética teológica de Bernardo de Claraval, que devia celebrar a memória do soberano defunto e, ao mesmo tempo, servir de memorial para a comunidade cisterciense que à volta dele se teria recolhido em oração, e para o qual se avançou com uma proposta de restauro e de recolocação dos dois suportes que hoje em dia sustentam a arca do infante Dinis;

- hipóteses relativas à cronologia, como no caso do túmulo da rainha Isabel e da sua neta, a infanta Isabel, fruto de um estudo comparativo e contextual destas duas obras;

- hipóteses relativas às personalidades artísticas dos mestres e aos obreiros envolvidos e também ao modus operandi aplicado, reconhecendo nomeadamente a influência da iluminura, quer a nível técnico quer decorativo e avaliando a possibilidade de 
D. Dinis del portogallo e Isabel d'Aragona in vita e in morte. Creazione e trasmissione della memoria nel contesto storico e artistico europeo - Giulia Rossi Vairo

colaboração de conversos e monges activos nos laboratórios e nos scriptoria cistercienses, tanto mais clara se considerarmos o facto de, tal como muitas vezes foi repetido ao longo do texto, originalmente todos os sepulcros serem policromos.

Contudo, para além das teses e das hipóteses formuladas, cuja validade será avaliada no tempo futuro, o que espero que possa despertar o interesse do leitor neste estudo são os retratos delineados dos protagonistas Dinis e Isabel, cujas extraordinárias personalidades se aprofundaram sob aspectos menos conhecidos, ou talvez até agora pouco indagados, e dos quais se tentou fazer sobressair a Humanidade com o propósito não de retirar-lhes o Mito ou a Santidade, mas simplesmente de restituí-los à História.

\section{COMO CITAR ESTE ARTIGO}

\section{Referência electrónica:}

ROSSI VAIRO, Giulia - "Apresentação de Tese / Thesis Presentation: D. Dinis del portogallo e Isabel d'Aragona in vita $e$ in morte. Creazione e trasmissione della memoria nel contesto storico e artistico europeo. Tese de Doutoramento em História da Arte, especialidade em História da Arte Medieval, apresentada à Faculdade de Ciências Sociais e Humanas da Universidade Nova de Lisboa, Novembro de 2014. Orientação do Professor Doutor José Custódio Vieira da Silva”.

Medievalista [Em linha]. No 19 (Janeiro-Junho 2016). [Consultado dd.mm.aaaa].

Disponível em

http://www2.fcsh.unl.pt/iem/medievalista/MEDIEVALISTA19/vario1909.html ISSN 1646-740X.

Medievalista online № 19| Janeiro - Junho 2016 @ IEM - Instituto de Estudos Medievais 12 
D. Dinis del portogallo e Isabel d'Aragona in vita e in morte. Creazione e trasmissione della memoria nel contesto storico e artistico europeo - Giulia Rossi Vairo

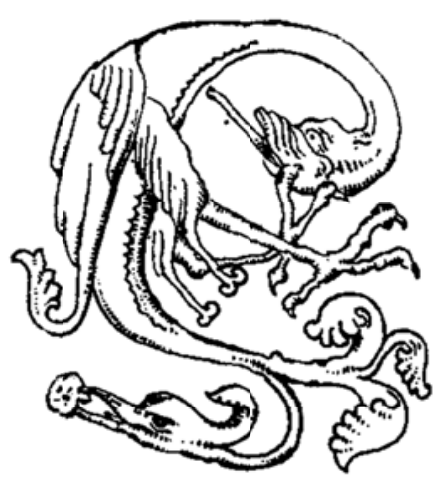

Medievalista online № 19| Janeiro - Junho 2016 (C) IEM - Instituto de Estudos Medievais 13

www2.fcsh.unl.pt/iem/medievalista 